\author{
Maria de Nazareth Baudel Wanderley \\ Doutora em Sociologia. Professora Visitante da UFPE. \\ wanvilar@uol.com.br
}

\title{
HOMENAGEM AO PROFESSOR MARCEL JOLLIVET \\ RESUMO
}

Em junho de 2001, o "Laboratoire Dynamiques Sociales et Recompositions des Espaces" — LADYSS organizou, na Universidade de Paris X- Nanterre, um colóquio para lançar o livro "Agriculture et ruralité au Brésil, un autre modèle de développement", organizado por Magda Zanoni e Hugues Lamarche e publicado pela Editora Karthala. Na ocasião, foi prestada uma homenagem ao Professor Marcel Jollivet, um dos fundadores do Groupe de Sociologie Rurale, que havia sido diretor do Laboratório por muitos anos e que acabara de se aposentar. Maria de Nazareth Baudel Wanderley, primeira orientanda do Professor Jollivet, foi escolhida para prestar a homenagem. O presente texto é o discurso por ela proferido na ocasião.

Palavras-chave: Sociologia Rural, campesinato, mundo rural.

\section{Tribute to Professor Marcel Jollivet}

\section{ABSTRACT}

In June 2001, the "Laboratoire Dynamiques Sociales et Recompositions des Espaces" — LADYSS organized, in the University Paris X — Nanterre, a colloquium to release the book "Agriculture et ruralité au Brésil, un autre modèle de développement", edited by Magda Zanoni and Hugue Lamarche and published by Karthala Printing House. During the occasion, it was paid tribute to Professor Marcel Jollivet, one of the founders of the Groupe de Sociologie Rurale, who had been director of the Laboratory for several years and had just retired. Maria de Nazareth Baudel Wanderley, the first student supervised by Professor Jollivet, was chosen to pay the tribute. The present text is the speech delivered by her in the occasion.

Key words: Rural Sociology, peasantry, rural world.

«O trabalho das ciências sociais, e em particular, da sociologia, é de saber ler este (tipo de) "crônica” da vida da sociedade; esta leitura não é tão fácil como pode parecer porque ela é de fato uma interpretação. O papel das ciências sociais é precisamente o de elaborar uma grade de leitura que torne inteligível este "ar do tempo", isto é, que permita distinguir-se de suas formas confusas, contraditórias, singulares, efêmeras - ou seja, em uma palavra, de sua opacidade - para compreendê-lo ou, dito de outra forma, dar-lhe um sentido».

Conta-se que, um dia, Dom Hélder Câmara, Arcebispo de Olinda e Recife, deveria homenagear um grande amigo em uma reunião como esta. Ele se perguntava: o que dizer para dizer tudo? E dirigindo-se a seu amigo, ele simplesmente disse: amigo, você sabe!

Hoje, tenho vontade de fazer a mesma coisa e, para dizer tudo, dizer simplesmente: Marcel Jollivet, você sabe!

Em janeiro de 1970, eu iniciava em Nanterre uma extraordinária experiência de formação intelectual de brasileiros, sob a direção de Marcel Jollivet. Reivindico ter sido a primeira. Desde então, que história foi construída cujo personagem central é Marcel Jollivet!

I - Este é o momento de formar o quadro geral e de construir uma visão de conjunto desta influência. Influência direta, em primeiro lugar, que se exerceu sobre aqueles, cujas teses foram orientadas por Marcel Jollivet. E para demonstrar o quanto ela foi frutífera, basta verificar os escritos que eles produziram, desde a defesa de suas teses e a produção dos estudantes que, por sua vez, eles orientaram no Brasil. É uma rede significativa, presente em várias universidades do País. Influência direta, também, através das missões que efetuou ao Brasil e dos seus textos publicados em nossas revistas especializadas.

Mas é preciso falar, igualmente, da influência, de uma certa forma, indireta, que se exerceu através do "Groupe de Sociologie Rurale” de Nanterre, que hoje se transformou no "Laboratoire Dynamiques Sociales et Recompositions des Espaces” — LADYSS. Quantos estudantes e professores brasileiros passaram por aqui e enriqueceram 
sua formação e sua experiência em contato direto com Nicole Eisner, Hugues Lamarche, Jean-Paul Billaud, Nicole Mathieu, Hélène Delorme, Marie Claude Herrerro e, antes deles, com Henri Mendras? (Quero aproveitar a ocasião para expressar, publicamente, o quanto eu devo pessoalmente ao Professor Henri Mendras, a quem envio uma palavra de reconhecimento e amizade)

Uma menção especial deve ser feita ao Acordo CAPESCOFECUB, assinado inicialmente com a Universidade Federal da Paraíba e, ampliado, em um segundo momento, às Universidades Federal do Rio Grande do Sul e Estadual de Campinas. Do lado francês, ele reunia, além dos pesquisadores de Nanterre, dentre os quais Hélène Delorme, que o coordenou em sua segunda fase, Bernard Roux, do INRA — uma das pessoas centrais deste acordo - e Rose Marie Lagrave, da EHESS, ela também importante parceira de seu grande sucesso.

Este programa nos impôs, sem dúvida, sobretudo em sua fase inicial, uma grande dose de sacrifício, em razão da precariedade da estrutura de acolhimento dos pesquisadores franceses no Brasil. Entretanto, apesar de todas as dificuldades, tenho a certeza que ele nos uniu em um longo e pioneiro processo de cooperação, que produziu frutos muito importantes. Trata-se de sua contribuição à consolidação dos Programas de Doutorado nas Universidades envolvidas, através da formação de seus professores e alunos, em programas de doutorado pleno, doutorado sanduíche e pós-doutorado. Trata-se, igualmente,

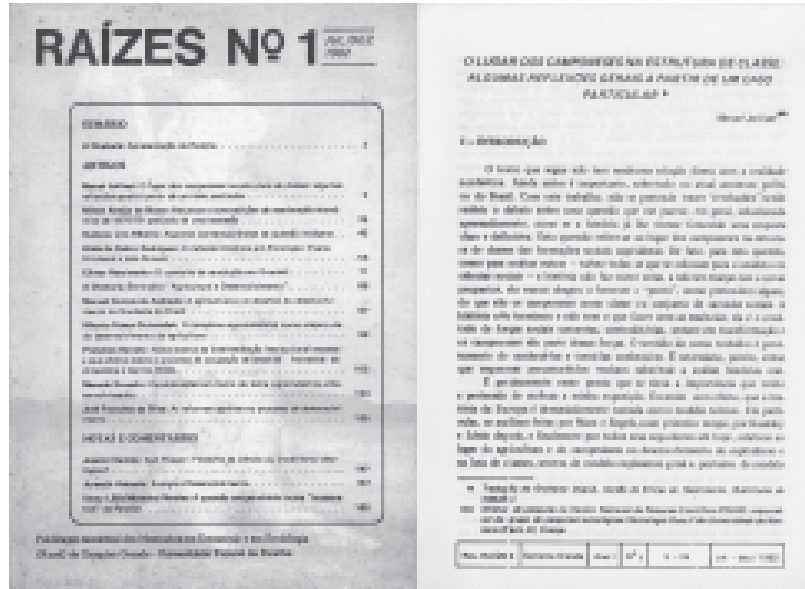

Imagens da capa do $1^{0}$ número da Revista Raízes e da página de rosto do seu artigo de abertura: "O lugar dos camponeses na estrutura de classes", de Marcel Jollivet, traduzido por Ghislaine Duqué. da importante produção de conhecimento. Além das teses defendidas, é preciso registrar os trabalhos coletivos, dentre os quais o estudo comparativo sobre a agricultura familiar, coordenado por Hugues Lamarche, que foi, sem dúvida, uma das principais expressões do Acordo.

Hoje, a cooperação franco-brasileira dispõe de meios mais eficazes, que a tornam mais leve, como é o caso do Acordo com o Programa de Desenvolvimento Rural da Universidade Federal do Rio Grande do Sul, em Porto Alegre.

Devo registrar que este encontro de Marcel Jollivet com o Brasil — não somente com o Brasil, por sinal — não significa, de nenhuma forma, um desvio "turístico" à via "natural" de sua pesquisa francesa. Pelo contrário, ela se inscreve como uma parte constitutiva de seu próprio objeto de estudos. Como ele afirmou, "Há alguma coisa de comum entre uma volta no tempo e uma análise comparativa. Após ter realizado esta investigação histórico francesa — refere-se aqui a sua participação na pesquisa sobre a história rural francesa eu desejei confrontar minhas análises sobre a França com outras realidades geográficas e nacionais (Portugal e Brasil, especialmente). É, intelectualmente, o mesmo estranhamento".

E o que dizer da influência da obra de Marcel Jollivet, hoje reunida no livro recentemente publicado, para aqueles que acompanharam sua construção? Não é, evidentemente, o caso de tentar a apresentação de qualquer síntese, ou mesmo de resgatar as linhas mestras de seu pensamento. Seria por demais longo e exigiria uma capacidade de síntese, que receio não conseguir demonstrar. Registraria apenas que sua obra foi fundamental para marcar dois grandes saltos qualitativos na Sociologia Rural. Por um lado, ao deslocar o eixo da interpretação, centrado no próprio mundo rural, para a própria dinâmica das forças sociais gestadas pelo capitalismo, sua reflexão desvenda os significados que assumem a agricultura, os agricultores e o meio rural nas sociedades modernas. A identificação destes "novos lugares” muito contribuiu para a afirmação da agricultura familiar como um fato social do mundo moderno, ultrapassando assim, a velha concepção da decomposição do campesinato, que desautorizaria qualquer interesse pelo seu estudo. Não se trata, portanto, da manutenção de um qualquer 
“arcaísmo sociológico e econômico”, mas, sobretudo da reprodução de um “camponês-na-história”.

Assim, "no agricultor o camponês continua adormecido". O que concede, com efeito, aos agricultores modernos a condição de atores sociais, construtores e parceiros de um projeto de sociedade - e não simplesmente objetos de intervenção do Estado, sem história - é precisamente a dupla referência à continuidade e à ruptura, ou, como diz Hugues Lamarche, a dupla referência aos modelos "original" e "final".

O segundo salto qualitativo corresponde à contribuição mais recente de Marcel Jollivet referente à nova percepção do "rural" como um espaço privilegiado de interação entre sociedade e natureza, isto é, o rural, enquanto meio ambiente. No momento em que — não somente na França, deve-se dizer - a idéia de um meio rural parecia perder seu poder explicativo, diante da vitoriosa "lei geral" da urbanização da sociedade, a afirmação da passagem "do rural ao meio ambiente" trouxe uma nova luz sobre o lugar do "rural" nas sociedades modernas.

Para além da contribuição científica, sob muitos aspectos pioneira e original, a lição que fica é a da profundidade e complexidade de sua abordagem teórico-metodológica, marcada, a meu ver, por quatro pares de princípios norteadores.

Em primeiro lugar, a busca incessante dos laços existentes entre a teoria geral e a interpretação dos fatos sociais. $\mathrm{O}$ pesquisador se fundamenta na referência a uma teoria geral, capaz de atribuir «o sentido geral dos fatos», sabendo que estes fatos são históricos e, portanto, devem ser situados em seu contexto histórico e explicados em «sua inevitável singularidade». Este procedimento permite que se percebam «os traços originais da história agrária» de um país e estabelece o campo no qual é possível efetuar comparações entre países diferentes.

Em segundo lugar, a sensibilidade para apreender as questões atuais colocadas às Ciências Sociais, pela própria sociedade, sem no entanto, perder a dimensão histórica dos fatos estudados. Um certo «ar do tempo» «longe de ser da ordem do contingente, se inscreve nos mecanismos de funcionamento e dos processos de evolução geral da sociedade”.

Raízes, Campina Grande, vol. 21, n0 02, p. 184-194 jul./dez. 2002
O terceiro par de princípios norteadores é conseqüência dos dois primeiros, por que ele reúne — e opõe — os conceitos de unidade e diversidade. Tendo em vista que a diversidade é um atributo crescente das sociedades modernas, cabe às Ciências Sociais a tarefa de compreender os mecanismos históricos que as produzem, vinculando-os ao mesmo tempo à unidade sempre reconstruída da explicação teórica.

Finalmente, o quarto par de princípios norteadores consiste na convicção do caráter pluridisciplinar e interdisciplinar dos estudos rurais que, longe de diluir a contribuição específica de cada disciplina, a tem como corolário, sobretudo quando a complementaridade dos olhares se impõe como exigência do próprio objeto de conhecimento. A este respeito, registre-se que à Sociologia, tal qual é exercida por Marcel Jollivet, cabe o papel fundamental de, reconhecendo a contribuição de outras disciplinas científicas, integrá-las em uma leitura de síntese da realidade social. Esta é, a meu ver, a marca mais significativa da obra de Marcel Jollivet: um misto de respeito pelos outros e de coragem de não ter uma obra somente sua, o que, de fato, só engrandece sua contribuição pessoal. É preciso ousar fazer isto.

$\mathrm{Na}$ verdade, estes quatro pontos, a que acabo de me referir, não são apenas princípios gerais. Eles formam a alma da pesquisa desenvolvida ao longo dos anos e é deles que é preciso tirar as lições propostas pelo pesquisador.

Vamos ver se aprendi a lição.

II - Vou inspirar-me no pensamento de Marcel Jollivet para refletir sobre a realidade brasileira. Para isto, seguirei o traço que ele mesmo indicou, por ocasião do colóquio franco-brasileiro realizado em 1982, ao propor os termos de um diálogo, que desde então não parou de revelar sua fertilidade: «procurar compreender o que, na sociedade considerada, tendo em vista sua própria história, faz com que a questão agrária se coloque ou não se coloque, que se coloque em tais ou quais termos ».

Num esforço de síntese, podemos falar, também no Brasil, de uma questão agrária e de uma questão rural.

III — A questão agrária se desdobra no Brasil em três questões. A primeira delas diz respeito ao lugar da agri- 
cultura e dos agricultores na sociedade brasileira. Tratase de compreender a agricultura como um espaço social, integrado em um projeto de sociedade: como a produção agrícola atende às necessidades da sociedade em seu conjunto, que formas sociais assumem a realização desta produção. Em outras palavras, que modernização da agricultura e que forças sociais são os agentes desta modernização.

No século XIX, a questão agrária emerge no seio da construção da nacionalidade brasileira e da formação de seu povo, passando por três momentos significativos: a independência (em 1822), que favoreceu a consolidação da elite dominante nacional, constituída, fundamentalmente, pelos grandes propietários fundiários; a adoção da Lei de Terras (em 1850), instrumento legal que, ao definir as condições de acesso à propriedade fundiária, estabeleceu por antecipação, o lugar na sociedade, de todos aqueles que deveriam esperar ainda 38 anos para que a escravidão fosse enfim abolida (em 1888), a abolição sendo, por conseguinte, o terceiro momento.

Diante de uma sociedade cortada em dois pela instituição da escravidão, não é de admirar que o francês Louis Couty, em visita ao Brasil, tenha afirmado que "o Brasil não tem povo”. A reação de Couty é compreensível. Ele era francês; em seu País natal, como nos ensina Marcel Jollivet, a sociedade moderna se consolidava e os camponeses, vencedores de uma longa batalha pelos direitos sobre a terra, construíam o apogeu social, econômico, cultural e político de suas sociedades rurais.

No Brasil, ao contrário, o século XIX consagrou a vitória da grande propriedade. Sua legitimação social era afirmada em nome de um projeto de modernização, cujos eixos eram dados, de um lado, pela importância de sua produção para a economia nacional e, de outro lado, pelas propostas civilizatórias, de “desbarbarização" dos agricultores, presos a práticas agrícolas rotineiras, freqüentemente percebidas como resultantes de um processo de regressão cultural. (Lourenço, 1998) Na verdade, o esforço ideológico de legitimação social da grande propriedade, não conseguia esconder os seus interesses primordiais, naquele momento: assegurar o controle da terra para, através dele, assegurar a manutenção dos mecanismos de controle da força de trabalho, agora sob a forma de "trabalho livre".
Deve parecer estranho, mais uma vez, a um pesquisador do rural francês, a afirmação de que a propriedade fundiária no Brasil é até hoje um "elemento organizador da atividade agrícola” e que ela está na base, ao mesmo tempo, de relações de produção — através das quais aciona a força de trabalho disponível para as atividades agrícolas — e de relações de distribuição — que asseguram ao proprietário a apropriação de parte importante do valor socialmente produzido, através, entre outras formas, dos recursos oferecidos pelas políticas agrícolas. Proprietários fundiários que são dirigentes de um processo produtivo; empresários capitalistas que são rentistas do solo. É através de paradoxos como estes que o pesquisador brasileiro navega para apreender este traço fundante da sociedade brasileira: "o caráter produtivo da agricultura é aqui subordinado à dinâmica criada a partir da propriedade da terra”. (Wanderley, 1995)

Na segunda metade do século XX, a agricultura foi modernizada, técnicas modernas de produção foram introduzidas e cada vez mais esta produção se integra nas redes agroindustriais e nos circuitos do comércio nacional e internacional. No entanto, o que mais surpreende é que esta modernização não tornou o capital livre de sua vinculação dependente — no caso das atividades agrícolas — da propriedade da terra. Bem ao contrário, nossa Lei de Orientação Agrícola — o Estatuto da Terra — “cristalizou a predominância do proprietário sobre o produtor". Neste sentido, o significado mais profundo da política de modernização da agricultura consistiu em "tornar a grande propriedade forte diante do projeto alternativo das classes dominadas e viável para o grande capital”. (Wanderley, 1995)

Assim, a agricultura brasileira marcha contraditoriamente em dois tempos: por um lado, ela deve enfrentar as crises geradas pela adoção do modelo produtivista de modernização, cujos efeitos se manifestam ao nível econômico, social e ambiental, como nos ensina Hugues Lamarche. Este caminho lhe outorga a marca da contemporaneidade; mas por outro lado, ela ainda não resolveu sua questão fundiária, estando, portanto, ainda, de um certo modo, presa ao Século XIX, ou início do Século XX, quando a maioria dos países hoje desenvolvidos, de uma maneira ou de outra, se desembaraçaram deste obstáculo ao desenvolvimento.

Para os que querem compreender em profundidade, não 
basta simplesmente registrar as melhorias do desempenho produtivo setorial, mas é absolutamente necessário explicar as conseqüências para a sociedade brasileira desta «modernização feita sob o comando da terra». (Wanderley, 1995) Conseqüências, antes de tudo, sobre o seu próprio processo de reprodução, para o qual a violência se torna um método coerente e natural. É interessante observar que a organização política representativa destes “empresários” — a União Democrática Ruralista - nasce, nos anos 80, no momento em que consideram que a propriedade da terra está ameaçada e é, portanto, enquanto proprietários - certamente sua face mais forte e profunda — que reagem às propostas de reforma agrária e às reformas constitucionais então em debate na sociedade brasileira. Uma frase, registrada por Regina Bruno em sua tese de doutorado, em elaboração, revela até onde se estende a defesa da propriedade «Se o problema é imolar vidas, que comecemos logo». (Bruno, 2002)

Conseqüências que afetam, também, as classes subalternas que vivem da agricultura. É preciso lembrar que estas classes, em sua expressão moderna — aqui incluídos os setores ligados à agricultura familiar — se constituíram, de fato, em um processo recente. Pelo menos os mais velhos dentre nós, somos contemporâneos da emergência de uma enorme massa de trabalhadores rurais que, a partir dos anos 60 perdeu o acesso, já precário, à terra e aos meios de sua subsistência e passou a viver da venda de sua força de trabalho. Da mesma forma, nos dias de hoje, sob os nossos olhos, os assentamentos de reforma agrária, que se disseminam em todo o território nacional, se constituem como sementeiras de um campesinato, cujo lugar na sociedade ainda está sendo conquistado.

Aqui, os paradoxos se avolumam: temos no Brasil assalariados do solo e camponeses sem terra. A respeito dos trabalhadores assalariados, o leque se abre sobre várias situações que parecem fugir ao modelo clássico. Seria o conceito de proletarização capaz de dar conta da emergência de uma grande massa de ex-assalariados, que se tornaram “desnecessários” ao capital e que perambulam pelas áreas rurais e pelas periferias das cidades, atravessando, algumas vezes, o País de Norte a Sul e de Leste a Oeste? O que dizer das crianças cujo trabalho penoso não somente na agricultura — representa a única e miserável renda que sustenta toda a família? E dos traba- lhadores «em situação análoga à escravidão», que se encontram nas grandes empresas agropecuárias, ditas modernas, que são apenas a parcela mais aberrante de um mesmo processo de controle e subordinação da força de trabalho agrícola?

Maria da Conceição D’Incao, em livro publicado em 1973, já revelara a natureza profunda destas contradições de nosso desenvolvimento rural: "acumulação e miséria" (Mello, 1973). Não se trata, como já se pretendeu, de efeitos paralelos de um progresso necessário e desejável, mas, como afirma Fernando Lourenço em sua tese de doutorado, da «ambivalência dos projetos de modernização, que propõem a emancipação, mas repõem a sujeição» (Lourenço, 1998). A proletarização é aqui confundida com a pauperização extrema, "proletarização" à brasileira, feita sob a base de intensa exploração da força de trabalho sem qualificação profissional, sem garantia de proteção efetiva das leis trabalhistas e com acesso precário aos bens e serviços fundamentais ao cidadão. Ousemos ir mais fundo nesta questão: como poderiam as formas sociais dominantes na atividade agrícola, gestar uma classe operária moderna?

Com os camponeses, a primeira dificuldade é de reconhecê-los. São inúmeros os testemunhos históricos de sua invisibilidade. Assim, os cientistas europeus, os viajantes, como são chamados, que visitaram o Brasil desde o século XVII e que foram os primeiros «brasilianistas», descrevendo minuciosamente suas paisagens, sua fauna e sua flora, pouco se interessavam pela «gente» que viam ao longo dos caminhos percorridos. Como afirma Carlos Rodrigues Brandão, «foi assim, como uma «sombra coletiva», que a imagem destes camponeses caboclos nos foi legada» (Brandão, 1984) «Estes homens — dizia Saint-Hilaire, aqui citado por Brandão — não pensam; vegetam como árvores, como erva do campo».

O discurso e os projetos de vida dos cultivadores pobres livres parecem incompreensíveis. E a resposta do século XIX lhes é extensamente dura: o extermínio, nas guerras camponesas de Canudos e Contestado; a sujeição ao trabalho nas plantações; a errância. Para utilizar uma expressão já consagrada: o cativeiro da terra.

Mas a invisibilidade continua. Quando, nos anos 70 do século XX, os governos militares lançaram um vasto programa de ocupação das fronteiras Norte e Centro- 
Oeste, o slogan adotado não tinha outro sentido. «Vamos levar homens sem terra para uma terra sem homens». Toda esta imensa região do país era, assim, percebida como vazia. A população lá residente, com suas raízes culturais profundas era, mais uma vez uma «sombra coletiva».

O mesmo vem acontecendo sob nossos olhos, a respeito da vasta área dos Cerrados. Vista como um "vazio demográfico, cultural e econômico", ela tem sido objeto de programas que pretendem incorporá-la produtivamente à economia nacional. Ora, como nos revela Maria Dione Carvalho de Moraes, esta área é, desde muito tempo, povoada por camponeses, cuja economia é um dos exemplos mais expressivos de uma agricultura tradicional "ecologicamente integrada", mas cuja visibilidade social é "eclipsada” pelo discurso e pela prática de intervenção dominantes. (Moraes, 2000)

O que dizer dos camponeses sem terra? «Foi preciso que muitas mortes acontecessem (outras ainda virão?) para que eles também deixassem de ser uma «sombra coletiva», vagamente percebida nos acampamentos das beiras de estrada, nas marchas para as cidades e nas ocupações de terras abandonadas, cujo potencial produtivo, social, cultural e político a sociedade insiste em desperdiçar» (Wanderley, 1995).

A negação do campesinato também é assumida por um certo discurso de esquerda, para o qual a questão camponesa se traduzia simplesmente no processo de sua decomposição, debate que se filiava em linha direta àquele que também aconteceu na França nos anos 60 e 70.

A versão mais recente desta discriminação é o recurso a seleções burocráticas, baseadas em tipologias que negam o status de agricultor a uma grande massa de trabalhadores da terra, renomeados «agricultores periféricos» ou «franja marginal» da população do campo. Ora, esta «categoria rural esquecida», como disse Maria Isaura Pereira de Queiroz, certamente a mais importante estudiosa do campesinato entre nós, sempre existiu na sociedade brasileira. Desde os «cultivadores pobres livres», registrados pelos historiadores do período colonial, até os agricultores familiares modernos da atualidade. Se a agricultura de subsistência foi considerada a "face oculta" da economia e da sociedade coloniais (Linhares \& Silva, 1981), sua presença no próprio campo da econo- mia agrícola é confirmada no passado e no presente. Em 1989, Angela Kageyama e Sonia Bergamasco, visando suprir a falta de dados estatísticos oficiais, elaboraram, pela primeira vez, um quadro geral da dimensão desta agricultura familiar. Baseadas no Censo Agropecuário de 1980, concluíram que $72 \%$ dos estabelecimentos agropecuários brasileiros eram familiares. (Kageyama \& Bergamasco,1989/90). O último Censo, realizado em 1996, atualiza esta informação: $85,2 \%$ dos estabelecimentos brasileiros são familiares (no Nordeste eles são 88,3\%). Dispondo de 30,5\% da superfície total dos estabelecimentos e recebendo apenas $25,3 \%$ dos financiamentos, esta forma social de agricultura é responsável por 37,9\% do valor bruto da produção agropecuária brasileira.

A presença destes agricultores tem também um caráter político. O "grito da terra", emitido pelos movimentos sociais rurais que se sucederam ao longo do tempo, ecoa para a sociedade brasileira as situações-limite em que muitos vivem. Ele é, antes de tudo, a expressão de camponeses, cujas terras foram desapropriadas para a construção de barragens elétricas; daqueles que sofrem os efeitos de desastres, tais como a seca do Nordeste; dos povos das florestas, ameaçados com a destruição de seu habitat, ou daqueles que permanecem no campo, simplesmente reproduzindo sua miséria vergonhosa em um país que se orgulha de suas riquezas. Mas o grito da terra também ecoa o projeto de vida destas famílias, que muitas vezes se expressa como uma utopia - a sede de terra, a que se referiu Oleg Stanek - cuja conquista supõe freqüentemente, o percurso de esdrúxulos caminhos — da errância migratória à permanência miserável — que parecem contradizê-la (Garcia Jr, 1990).

A demanda da reforma agrária, reiteradamente posta mais um paradoxo? - aparece a muitos como uma grande surpresa. Não só àqueles diretamente interessados em manter o significado da propriedade fundiária, mas também àqueles que tentaram nos convencer que a modernização da agricultura havia revertido o poder tradicional dos velhos latifundiários pela predominância das modernas formas de capital. A questão agrária fora resolvida, pois ela não impedia, como querem muitos, a expansão do capital. No entanto, as ambigüidades deste processo de modernização saltam aos olhos ao sabermos que, no início dos anos 90, cerca de 185 milhões de hectares, isto é, $41 \%$ das terras aptas para a agricultura, eram terras improdutivas, isto é, deixadas em abandono (INCRA, 1992). 
Os movimentos sociais, particularmente o Movimento dos Trabalhadores Rurais Sem Terra têm, sem dúvida, o grande mérito de colocar o dedo na ferida e revelar à sociedade o quanto o processo de modernização foi incapaz de integrar ao desenvolvimento os recursos disponíveis no país. Neste caso sim, há homens sem terra demandando terras sem homens!

Duas imagens veiculadas pela televisão há poucos anos atrás me pareceram extremamente expressivas de uma nova realidade que emerge no meio rural brasileiro. Primeira imagem: o então Presidente do INCRA, ao visitar um assentamento de reforma agrária em São Paulo, foi recebido com um almoço. A televisão mostrou a fartura daquela mesa, insistindo que todos aqueles alimentos haviam sido produzidos naquele "novo" espaço produtivo e por aqueles "novos" agricultores. Estes mesmos agricultores — era possível concluir — que passaram dois anos acampados na beira da estrada esperando receber a terra, vistos então com temor por todos aqueles que por lá passavam. Segunda imagem: dois anos após o massacre de Eldorado de Carajás — quando 19 trabalhadores sem terra foram assassinados no Estado do Pará - a televisão mostra a primeira colheita feita pelos que foram assentados posteriormente naquela terra: ela jamais havia sido cultivada; era a primeira vez que dela brotava algum produto.

Antes de abordar o segundo tema, permito-me concluir esta primeira parte citando um poema de um dos maiores poetas brasileiros, João Cabral de Melo Neto:

_ O cassaco de engenho
de longe é como gente:
— De perto é que se vê
o que há de diferente.
— O cassaco de engenho,
de perto, ao olho esperto:
— Em tudo é como homem
só que de menos preço
— Não há nada de homem
que não tenha, em detalhe
e tudo por inteiro,
nada pela metade.
- É igual, mas apesar,
parece recortado
com uma tesoura cega
de alfaiate barato

Raízes, Campina Grande, vol. 21, nº 02, p. 184-194 jul./dez. 2002
(Do poema: Festa na Casa Grande: ritmo deputado: sotaque nordestino)

IV - O segundo tema diz respeito à significação do mundo rural para a sociedade brasileira. (Falarei dela rapidamente, pois este tema será objeto de minha próxima intervenção neste seminário). Uma primeira e principal polarização se constrói, que perpassa toda a história brasileira: a que opõe o mundo civilizado das cidades litorâneas ao "sertão", grande espaço vazio ou povoado por homens "rudes" e "incivilizados". Que lentidão tem esta heróica missão — ainda inconclusa - atribuída ao litoral urbano, de conquistar e civilizar o Brasil? Até hoje, este corte se perpetua, fomentando em sua base, o desenvolvimento de processos sociais de grande significação, como a colonização das regiões de fronteira, a elaboração de identidades e estigmas, a emergência de novas alianças e conflitos sociais.

A tese de doutorado de Estado de José Vicente Tavares dos Santos, defendida em Nanterre, sob a orientação de Marcel Jollivet, permanece como o estudo mais completo a respeito deste tema. Para ele, o Estado brasileiro, através do processo de colonização atuou, de um lado, junto aos camponeses - no caso, os camponeses do Sul do País - acenando com um projeto que pretendia transformar a sua "sede de terra" em um "sonho de terra"; de outro lado, na própria área da fronteira, criando "um vazio social, politicamente construído”, o que permitiu a implantação das novas zonas produtivas desejadas (Santos, 1987).

Mas o rural não é apenas este suposto vazio longínquo da fronteira, o nosso far west. Uma segunda polarização se estabelece entre o mundo urbano, especialmente o das grandes metrópoles — a cidade de São Paulo possui atualmente 10 milhões de habitantes - e o mundo rural. É curioso observar que o estudo do mundo rural foi praticamente abandonado pelos pesquisadores brasileiros, desde o início dos anos 70. Havia, sem dúvida, a crítica aos limites dos estudos de comunidade, procedimento metodológico então predominante nas pesquisas sobre as pequenas comunidades; havia, igualmente, a necessidade de afirmar — corretamente, sem dúvida a progressiva dominação do mundo urbano-industrial sobre o conjunto da sociedade brasileira. Mas havia, também, uma certa pressa dos brasileiros para negar o 
«rural» — visto como lugar do atraso, da incivilidade, do obscurantismo, da miséria e da subordinação política ou para tentar superá-lo, com um projeto de desenvolvimento, sempre definido como processo de urbanização.

Não é inútil lembrar que a população urbana só ultrapassa os habitantes do campo nos anos 60; pela primeira vez, com efeito, o Censo de 1970 conta $56 \%$ de "urbanos" no País. Ainda recentemente, o anúncio dos resultados do Censo Demográfico de 2000 fez ecoar, por todos os meios de comunicação, o orgulho dos brasileiros, de constatar que um pouco mais de $80 \%$ de sua população vivem nas cidades. Finalmente, eis-nos civilizados!

O paradoxo a respeito deste tema surge do contraste entre esta atitude de negação e a impressionante presença do rural na vida social e cultural brasileira. A começar pela própria memória pessoal e familiar: é possível afirmar que boa parte dos brasileiros com mais de 30 anos já viveu (ou visitava com freqüência) — no meio rural ou em pequenos municípios, onde estão suas raízes familiares. Mesmo se esta memória parece a muitos como distante.

Isto me leva a não esperar o fim desta parte e antecipar sua ilustração literária.

Gostaria de lembrar-lhe um conto de Aníbal Machado, cujo título é "Viagem aos seios de Dúlia”. É a história de José Maria, um aposentado que, vivendo no Rio de Janeiro, decide, para dar sentido aos seus velhos dias, voltar à sua cidadezinha natal, para rever Dúlia, a jovem que, muitos anos antes, lhe havia exibido generosamente seus belos seios, durante uma procissão solene. Não falarei aqui, infelizmente, da antiga emoção de jovem José Maria, que "durou alguns segundos, (mas que) está durando uma eternidade”, nem de sua profunda tristeza, quando, tanto tempo depois, ele se deu conta de como os seios da agora idosa Dúlia haviam murchado. O que me interessa, aqui, neste conto, é sobretudo, a reconstituição do penoso e longo caminho de volta ao mundo da infância de José Maria. Mesmo sob o impulso de uma motivação intensa, ele não pode evitar exclamar: "como fica longe o lugar do passado!" É, de fato, freqüentemente como um lugar distante no tempo e no espaço, que o mundo rural — o campo e suas pequenas cidades - está registrado na memória das pessoas. \{Machado, Aníbal. Viagem aos seios de Duília. IN: MORICONI, Ítalo (org.) Os cem melhores contos brasileiros do século. Rio de Janeiro, Objetiva, 2000. p. 107-124.\}
É impossível, por outro lado, desconhecer o quanto este mundo rural está fortemente presente em quase todas as manifestações culturais brasileiras: a literatura, o teatro, o cinema, as artes plásticas. Sem falar na própria arte popular, originária em grande parte deste mesmo universo. Permito-me citar um exemplo, que nos diz respeito: lembro-me bem do espanto e da emoção que Marcel Jollivet sentiu quando ele ouviu o som de um carro de boi, que abria o filme Vidas Secas, de Nelson Pereira dos Santos, um som que precedia as imagens do filme e que parecia a ele fora do tempo e do espaço.

Que sentido pode ter, então, a busca do pai, que conduziu o pequeno Josué, do Rio de Janeiro até o sertão de Pernambuco, que pudemos acompanhar no recente filme Central do Brasil, de Walter Moreira Sales?

Além, portanto, da questão agrária, o Brasil tem a resolver sua questão rural. Esta tem, na minha opinião, três dimensões centrais. A primeira consiste na manutenção de uma situação de extrema pobreza que, sem ser exclusiva, se concentra no meio rural. De fato, o Brasil está longe de ter atingido qualquer paridade social entre as populações urbanas e rurais. Vejamos rapidamente, alguns dados desta realidade:

- em 1995, 25\% da população rural viviam abaixo da linha de pobreza;

- enquanto a população rural correspondia, naquela data a cerca de $20 \%$ da população total do país, estavam no campo mais de $24 \%$ de todos os pobres brasileiros (Rocha, 1998);

- os pobres se concentram sobretudo na região Nordeste: $44,3 \%$ deles vivem nesta região, enquanto os nordestinos são apenas 30\% dos brasileiros (Rocha, 1998);

- os municípios brasileiros com menor Índice de Desenvolvimento Humano são precisamente pequenos municípios do Nordeste, cuja população vive essencialmente da agricultura.

Não resta dúvida que a população rural ainda é a principal vítima da pobreza, do isolamento e da submissão política.

A segunda dimensão da questão rural diz respeito à gestão social dos espaços rurais. Estes não dispõem de nenhuma autonomia e sua gestão é efetuada a partir da cidade e, sem dúvida, sob a ótica da cidade. Apesar disto, 
algumas transformações recentes estão afetando progressivamente as relações de poder local. Assim, no que se refere aos aspectos político-institucionais, a Constituição Federal de 1988 combinou o princípio de uma significativa descentralização administrativa — que atribui à esfera municipal, um novo e importante papel nas suas relações com os Estados e a União - com o princípio de uma representação popular direta, sob a forma de Conselhos locais, que passam a compartilhar com as autoridades eleitas, a responsabilidade da destinação dos recursos públicos. Mesmo considerando a enorme capacidade de manipulação política, estes conselhos são, sem dúvida, o embrião de uma nova correlação de forças políticas locais, através das quais grupos organizados da sociedade civil podem enfrentar os tradicionais "donos do poder".

É possível afirmar, por outro lado, que existe hoje, em grande parte do meio rural, um ambiente de maior efervescência social, política e cultural. Este ambiente é a conseqüência de uma série de fatores que se somam: a multiplicação de associações, organizações representativas e movimentos sociais rurais; a presença de diversos e numerosos mediadores, nos diferentes campos da vida social local; a valorização crescente das manifestações culturais populares. Além disso, a população rural está hoje menos isolada do que no passado. Mesmo ainda de forma incipiente, há a registrar uma melhoria relativa das vias de comunicação; a expansão da rede elétrica permitiu o acesso à televisão, cujas antenas parabólicas mudaram, em alguns lugares, a própria paisagem rural. Embora, para muitos, a parabólica tenha o efeito de “desruralizar" o campo, descaracterizando-o, não se pode esquecer que ela, ao mesmo tempo, constitui um estímulo à permanência da população rural, agora em condições de ampliar seu horizonte, em seu próprio lugar de vida.

Este dinamismo se acentua naqueles municípios onde existem assentamentos rurais, sobretudo aqueles mais bem sucedidos. Além da expansão da produção local freqüentemente os assentamentos se instalam em áreas antes improdutivas — estes novos agrupamentos repercutem sobre a vida local, pelo menos em dois níveis: por um lado, dispondo dos recursos financeiros destinados à reforma agrária, os assentamentos contribuem para uma maior circulação monetária no município, sobretudo nos pequenos municípios; por outro lado, os agricultores neles instalados, vindos de uma luta vitoriosa pelo acesso à terra, possuem, em geral, uma grande capacidade de reivindicação e um grau elevado de participação na vida política e social do município. Uma anedota se tornou clássica, nestes meios: ela conta a história dos camponeses sem terra, que se viam rejeitados pela população local, até o momento em que, instalados em suas novas terras, receberam recursos financeiros do programa de reforma agrária. Vistos a partir de então como possíveis consumidores e mesmo como investidores locais, eles foram recebidos solenemente pelo diretor da agência bancária, que gentilmente lhes ofereceu um cafezinho.

O meio rural se constitui hoje, portanto, com uma intensidade inusitada, como um espaço de construção da democracia; não é mais necessário abandoná-lo, para aceder às condições mínimas da cidadania. Sem ilusões, é claro. Tudo está no começo e o começo é lento. Mas é um começo. Tudo isto exige uma grande sensibilidade aos pesquisadores do rural, para que sejam capazes de observar este processo e de perceber as novas questões que ele põe à sociedade. Em que medida as populações rurais dispõem de meios para se expressar? Qual é o seu projeto de sociedade? Quem são os novos mediadores? Estes mediadores conseguem, efetivamente, falar em nome das populações rurais referidas?

Finalmente, a terceira dimensão do rural introduz a reflexão sobre o meio ambiente. $\mathrm{Na}$ verdade, não pretendo aqui abordar esta problemática em seu sentido mais global, nem mesmo indicar suas questões maiores que, no Brasil, estão ligadas à destruição histórica dos grandes ecossistemas, tais como a Floresta Atlântica e Amazônica, a zona semi-árida do Nordeste e os Cerrados, à degradação dos meios urbanos, especialmente das grandes cidades e à poluição em grau elevado dos recursos hídricos. Pretendo, simplesmente, propor algumas reflexões sobre as conseqüências sobre o meio ambiente das formas dominantes de gestão do meio rural e de exercício da atividade agrícola.

O Brasil enfrenta hoje os efeitos nocivos do modelo de desenvolvimento historicamente predominante e se interroga sobre as formas "alternativas" de agricultura e de gestão do espaço rural, do ponto de vista da população e do meio ambiente. Historicamente, confiante na certeza da abundância e da qualidade natural das terras, a grande propriedade combinava a exploração extensiva com o 
caráter predatório do uso do solo. A tal ponto que, ainda no século XIX, em certas regiões do país, o valor de uma propriedade dependia em grande parte da dimensão de superfície não explorada de que dispusesse, que apontava mais para a capacidade de expansão futura de suas culturas do que propriamente para sua efetiva ocupação. (Fragoso, 1983).

A adoção do chamado "modelo produtivista" de modernização da agricultura, longe de arrefecer, agravou o uso predatório dos recursos naturais. A mudança do padrão tecnológico encontrava, de fato, grandes obstáculos: além da importância da grande propriedade, à qual ele estava associado, há a considerar o peso de instituições nacionais, tais como a EMBRAPA, que no início dos anos 70 introduziu os princípios da revolução verde no país e realizou as pesquisas necessárias à sua adaptação às condições locais de produção. Estas instituições se opunham a toda experiência de agricultura, dita "conservacionista”, expressão com forte conotação pejorativa, sempre referida como oposta aos avanços da ciência e defendida por pessoas sem compromisso com o desenvolvimento brasileiro.

A preocupação com esta situação não é recente, no Brasil, mas, durante muito tempo ela correspondia sobretudo a vozes isoladas de alguns estudiosos do desenvolvimento brasileiro. Júlia Guivant chega a afirmar, em artigo publicado em 1994, que a própria Sociologia Rural brasileira esteve ausente deste debate. "A disciplina não assumiu ainda esta questão, tendendo a considerá-la secundária entre os demais efeitos socioeconômicos do modelo de desenvolvimento sobre as diferentes classes sociais no meio rural e as unidades produtivas familiares" (Guivant, 1994). Atualmente, no entanto, pode-se dizer que, apesar da persistência dos problemas, a consciência da responsabilidade social sobre o meio ambiente vem ganhando várias batalhas no Brasil: no campo legislativo, no campo político, no campo das reivindicações sociais. Há muitas experiências positivas, muitas das quais de vanguarda, que estão sendo feitas por associações de agricultores, organizações não-governamentais e mesmo por instituições públicas. A EMBRAPA é hoje um dos espaços privilegiados deste debate. No meio acadêmico, a multiplicação recente, em todo o país, de cursos de graduação e pósgraduação e de linhas de pesquisa, centrados neste tema, é apenas um dos indicadores desta mudança que se pode registrar na agenda nacional das pesquisas em curso.

Para concluir, direi que é absolutamente urgente que a sociedade brasileira aprofunde o debate sobre que agricultura e que rural ela deseja. Um debate que deve começar pelo questionamento da legitimidade de seus representantes legais — os autodenominados parlamentares ruralistas - que nem sequer fazem parte da população rural, uma vez que na maioria dos casos, vivem nas cidades e percebem seus domínios como uma "terra de exploração".

Um debate que possa gerar um novo pacto social, formulado em torno de dois eixos centrais. Em primeiro lugar, que o rural é uma qualidade, que se exprime, sobretudo enquanto um patrimônio natural, social, cultural, do qual é preciso assegurar a integridade e a reprodução. Em segundo lugar, que a agricultura alternativa sustentável deve se impor como uma proposição de síntese, diante das questões acumuladas ao longo do tempo e que pode ser resumida da seguinte forma: vencer o desafio ainda posto da quantidade — a segurança alimentar aparece aqui com toda sua importância - e, ao mesmo tempo, vencer o outro desafio, já urgente, da qualidade, dos produtos, dos processos de produção e da vida dos próprios agricultores.

A construção desta nova agricultura - este é o tema deste seminário - é, de fato, o objetivo de um pacto social que possa associar as populações dos campos e das cidades, mas que parece não ser ainda bastante explicitado na sociedade brasileira.

Como Marcel Jollivet, eu interrogo: quem assinará este pacto?

Eu falei do mestre e do pensador. Sobre o amigo Marcel Jollivet, tomo a liberdade de recitar a letra de uma canção de Milton Nascimento

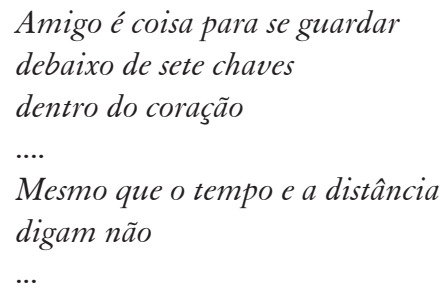


Qualquer dia, amigo

A gente vai se encontrar.

Marcel Jollivet, este dia chegou!

\section{BIBLIOGRAFIA}

BRANDÃO, Carlos Rodrigues. BRANDÃO, Carlos Rodrigues. Ideologia das classes subalternas. IN: PAULINO, A Y. ASCIUTTU, C. SALES, T. Revisão crítica da produção sociológica voltada para a agricultura. S.Paulo, ASESP/CEBRAP, 1983.

BRUNO, Regina. Senhores da terra, senhores da guerra; a nova face política das elites agroindústriais no Brasil. Pref. José de Souza Martins. R. Janeiro, Forense Universitária/UFRRJ, 1997.

BRUNO, Regina. O ovo da serpente: monopólio da terra e violência na Nova República. Campinas, UNICAMP. 2002. Tese de Doutorado.

FRAGOSO, João Luis. Sistemas agrários em Paraiba do Sul (1850-1920). 1983. Tese.

GARCIA JR., Afrânio Raul. Sul: o caminho do roçado; estratégias de reprodução camponesa e transformação social. R. Janeiro, Marco Zero, Brasilia, CNPq, 1989, 285 p.

GUIVANT, Júlia. Encontros e desencontros da Sociologia Rural com a sustentabilidade agrícola: uma revisão bibliográfica. BIB (Boletim Informativo e Bibliográfico de Ciências Sociais), Rio de Janeiro, (38), 51-78, 1994

IBGE. Censo Demográfico 2000.

INCRA. Estatísticas cadastrais anuais; 1992. Brasília, 1992.

JOLLIVET, Marcel. Pour une science sociale à travers champs; paysannerie, ruralité, capitalisme (France XX e. siècle). Paris, Arguments, 2001. 400 p.

JOLLIVET, Marcel. O lugar dos camponeses na estrutura de classes: algumas reflexões gerais a partir de um caso particular. Raízes, Revista de Ciências Sociais e Econômicas, Campina Grande (UFPB) (1): 5-24, jul/dez. 1982.

Raízes, Campina Grande, vol. 21, nº 02, p. 184-194 jul./dez. 2002
JOLLIVET, Marcel. PAVÉ, Alain. O meio ambiente: um campo de pesquisa em formação. Raízes, Revista de Ciências Sociais e Econômicas, Campina Grande (UFPB), XV (12): 3-13,jan. 1996.

KAGEYAMA, Angela, BERGAMASCO, Sonia M.P. A estrutura de produção no campo em 1980. Perspectivas, S.Paulo, (12/13): 55-72, 1989/1990.

LINHARES, Maria Yeda. SILVA, Francisco Carlos Teixeira da. A problemática da produção de alimentos e das crises numa economia colonial. IN: História da agricultura brasileira; combates e controvérsias. S. Paulo, Brasiliense, 1981. p. 107-170.

LOURENÇO. Fernando Antônio. Agricultura ilustrada; ambivalência do reformismo agrícola no Brasil (177019220). Campinas, UNICAMP. 1998. Tese de Doutorado)

MELLO, Maria Conceição d'Incao e. O bóia-fria: acumulação e miséria. Petrópolis, Vozes, 1973. 154 p.

MORAES, Maria Dione Carvalho. Memórias de um sertão desencantado; modernização agrícola, narrativas e atores sociais nos cerrados do Sudoeste Piauiense. Campinas, UNICAMP. 2000. (Tese de Doutorado)

QUEIROZ, Maria Isaura Pereira de. Uma categoria rural esquecida. Revista Brasiliense, S. Paulo, (45): 83-97, 1963.

ROCHA, Sonia. Desigualdade regional e pobreza no Brasil: a evolução - 1981/95. Rio de Janeiro, IPEA, junho 1998, 21 p. (Texto para Discussão, 567)

SANTOS, José Vicente Tavares dos. "Matuchos", le rêve de la terre. Université de Paris, X, Nanterre, 1987. (Tese de Doctorat d'Etat). (Edição brasileira: Matuchos: exclusão e luta; do Sul para a Amazônia. Petrópolis, Vozes, 1993. $282 \mathrm{p}$.

WANDERLEY, Maria de Nazareth Baudel. Les impasses de 1 'agriculture moderne au Brésil. Cahiers du Brésil Contemporain, Paris, 115-137, 1995. (Número Especial: 30 Ans des Questions Agraires au Brésil, org. Ricardo Abramovay). 